\title{
EMMANUEL MOUNIER E PAULO FREIRE: UM ESTUDO SOBRE A INFLUÊNCIA EPISTEMOLÓGICA DO PERSONALISMO SOBRE O PENSAMENTO PEDAGÓGICO DE PAULO FREIRE
}

\author{
Henrique Klenk ${ }^{1}$
}

\section{RESUMO}

Com o presente artigo, fruto de uma pesquisa realizada no âmbito do PPGE-PUCPR, pretendemos sinalizar, a partir de pesquisa bibliográfica, com base na hermenêutica como metodologia, o fato de que o Personalismo de Mounier, em particular aquele que aparece nas obras Revolução personalista e comunitária e $O$ personalismo, esteve presente nas ideias pedagógicas de Paulo Freire e que elas se refletiram nas suas categorias epistemológicas e na elaboração de seu método de alfabetização de adultos. Para isto, propomo-nos demonstrar como o personalismo entra no ideário brasileiro, sobretudo, por meio dos movimentos sociais católicos ligados à Ação Católica. Nossa intenção é mostrar que Freire teve dois tipos de influência do personalismo em sua obra: a primeira se deu pelo fato de ele ter estado em contato com os movimentos sociais católicos e bebido indiretamente das idéias de Mounier. A segunda pela leitura direta feita por Freire das obras do Personalista francês. Em seguida, analisaremos a presença do pensamento personalista presente na obra Educação e Atualidade Brasileira, livro que representa a primeira sistematização teórica feita por Paulo Freire antes do período em que foi exilado. Palavras-chave: Personalismo; Alfabetização de adultos; Movimentos sociais católicos; Ação Católica.

\section{EMMANUEL MONIER AND PAULO FREIRE: A SEARCH ABOUT THE EPISTEMOLOGICAL INFLUENCE OF THE PERSONALISM ON THE PEDAGOGICAL THINKING OF PAULO FREIRE}

\begin{abstract}
With this article, the result of a survey performed under the PPGE - PUCPR, we intend to signal, from literature, based on hermeneutics as a methodology, the fact that the personalism of Mounier, especially that appears in the works: Personalist and Communitarian Revolution and The Personalism, was present in the pedagogical ideas of Paulo Freire and they were reflected in their epistemological categories and it helps developing his method of adults literacy. For this, we propose to demonstrate how personalism enters into the Brazilian thinking, especially through the Catholic social movements linked to Catholic Action. Our purpose is to show that Freire had two kinds of influence of personalism in his work: the first was due to the fact that he had been in contact with Catholic social movements and be indirectly influenced by ideas of Mounier. The second by reading the works done by the French Personalist. Then, we analyze the presence of personalist thought present in the work Education and Brazilian Actuality, a book that is the first theoretical systematization made by Paulo Freire before the period in which he was exiled.
\end{abstract}

Key words: Personalism; Adults literacy; Catholic Social Movements; Catholic Action. 


\section{INTRODUÇÃO}

O Personalismo de Mounier atravessa o ideário intelectual do período pós-guerra juntamente com ideias de outros pensadores existencialistas. A ele se devem também as tentativas de análise da situação nacional por parte de intelectuais brasileiros, entre eles o próprio Paulo Freire.

Ruedell observa que o Personalismo surge como um movimento que tem em Emmanuel Mounier seu porta-voz e que anuncia renovação para a civilização do ocidente de acordo com os anseios da juventude da época. Ainda afirma que para tal, "assume principalmente um processo de conscientização das pessoas, no sentido de restaurar a liberdade e a dignidade humanas" (1985, p.30). São fatos que também encontramos nas obras e no testemunho de vida de Paulo Freire quando da sua participação nas campanhas de alfabetização no Nordeste do país. Para ele, a conscientização se daria pela descoberta da palavra, bem como por sua pronúncia, a fim de que o oprimido se aproprie do mundo (FREIRE, 1996).

Paulo Freire vinha de uma família na qual os princípios do cristianismo vigoravam. Tais fatores o tornaram um "cristão militante" (BEISIEGEL, 1989). Daí que o Personalismo como filosofia para mudança social, por meio do engajamento, encontrou abrigo na sua teoria e na sua prática educacional.

O engajamento no temporal, assumido pelos jovens católicos (JUC), sob a perspectiva personalista, é uma importante referência na vida do educador. Ele mesmo se tornou um intelectual engajado na luta pela transformação da realidade por meio de seu sistema de alfabetização. Assim, acompanhou o processo de engajamento dos jovens católicos no MEB, por exemplo, bem como na experiência de Angicos, posteriormente.

\section{A PRESENÇA DO PERSONALISMO DE MOUNIER NO IDEÁRIO DOS MOVIMENTOS SOCIAIS CATÓLICOS}

Gerhardt $(1996)^{2}$ mostra a relação entre Freire e os jovens católicos radicais, bem como a posição desses no momento histórico nacional:

[...] os estudantes cobravam reformas fundamentais na universidade, na saúde, nos serviços públicos e na moradia. Diferentemente de tempos anteriores, em que os estudantes apenas propunham soluções, agora visitavam favelas para discutir os problemas com seus moradores e iniciavam campanhas para superar as miseráveis condições da vida cotidiana. Nesta época, na universidade, Freire familiarizou-se mais e mais com as ideias do movimento católico radical, aprofundando seus estudos dos clássicos católicos, nacionais e estrangeiros, e sistematizando seu próprio modo de pensar e agir (GERHARDT, In: GADOTTI, 1996, p.153).

Vanilda Paiva afirma que Freire se liga aos jovens católicos na década de 1960, ambos motivados pela "contra massificação" do homem. A autora explica que os jovens católicos encontraram "no método Paulo Freire exatamente um instrumento do personalismo contra a massificação" (Paiva 1980, p.107).

Paiva ainda explica que Freire não fazia parte das gerações da JEC e da JUC, que passaram do "Maritainismo" ao Personalismo de Mounier, criticando posteriormente àquele. No entanto, "recebeu o impacto desta evolução sem ter dela participado" (1980, p. 107). 
Além disso,

Freire parece ter se ligado aos jovens que se apoiaram mais no jovem Mounier, aquele que se recusou a pensar em estratégias para a conquista do poder político, que via com grande desconfiança os grupos empenhados em tal tarefa (os "massificadores"), enfatizando a importância do trabalho educativo a longo prazo (1980, p. 107).

Por isso, a ação pedagógica de Paulo Freire priorizou a tomada de consciência, a passagem da consciência ingênua para a transitiva e desta para a consciência crítica, por meio de uma educação libertadora. Somente assim, a massa, agora povo conscientizado, poderia ter uma participação transformadora na vida política nacional.

Beisiegel observa que "para os militantes da JUC, primeiro, e da Ação Popular (AP), logo depois, a linguagem de Paulo Freire era familiar e confiável, suas propostas eram as propostas do cristianismo [...]" (BEISIEGEL, 1989, p. 226), afirmando ainda que "suas primeiras atividades educativas vieram sendo acompanhadas pelo seguro amadurecimento de uma particular interpretação cristã do homem e do mundo" (1989, p. 283), a partir das leituras feitas em Mounier.

Portanto, estes pontos de afinidade do pensamento de Paulo Freire e dos movimentos sociais, no caso, a JUC, permitem constatar que ambos tiveram os mesmos referenciais teóricos para se fazer presentes no mundo. Desse modo, fica difícil perceber a intimidade entre estes, sem que se tenha em mente que ambos estavam inspirados pelo Personalismo, um Personalismo que clamava incessantemente pelo engajamento em favor do oprimido.

A difusão das ideias de Mounier no Brasil é vista em primeiro plano pela influência de sua filosofia nas análises da realidade brasileira feitas pelos Isebianos e pela JUC, por exemplo. Tal análise, pautada na metodologia do "ver, julgar e agir" da Ação Católica tem no pensamento de Mounier, os elementos para interpretar a realidade (ver), tomar consciência (julgar) e propor uma atitude revolucionária para a transformação (agir).

Neste sentido, Wanderley afirma:

[...] a JUC avançou na análise da realidade brasileira, tendo como balizamento temas da superação do subdesenvolvimento e perspectivas de um desenvolvimento nacional, rompendo com o capitalismo e medidas que desenhavam um horizonte socialista. No conjunto prevalecia um humanismo cristão, com uma mescla de componentes da filosofia personalista, do populismo, do pensamento social católico, da critica ao capitalismo [...] (1984, p.386).

Dessa maneira, o Personalismo fez parte das ideias básicas da JUC, bem como do MEB, mais profundamente daquela do que deste. Explica-se, pois em se tratando de uma ação sobre a realidade concreta, a JUC ofereceu uma formação teórica para a pequena burguesia, oferecendo-lhe as ferramentas imprescindíveis para levá-la a tomar consciência de si e da realidade, enquanto o MEB partiu "da realidade do povo" (WANDERLEY, 1984, p. 396). É isso que reflete essa realidade, tendo como referência elementos constitutivos do Personalismo de Mounier.

No primeiro encontro nacional de coordenadores do MEB, segundo Wanderley (1984, p. 404), aparecem na temática a ser discutida alguns pontos que a aproximam da filosofia de Mounier. Embora isso fosse de modo velado, pois o evento tinha como temas 
centrais: "a) realidade nacional e internacional; b) a educação na perspectiva da consciência histórica; c) processo de conscientização e politização". Esses são temas que não escapam do Personalismo de Emmanuel Mounier.

A preocupação com a massificação do ser humano, demonstrada por Mounier na crítica aos regimes totalitários também é encontrada nos trabalhos de Freire. Está presente, sobretudo, na análise da realidade brasileira feita pelo autor sobre o período em que tinha início o processo de desenvolvimento industrial do país. Para Paiva (1980), esse é um dos pontos mais expressivos do Personalismo na obra de Freire. Seu método de alfabetização, por exemplo, será uma inovação contra a maioria dos métodos utilizados à época, porque para Freire

[...] a educação é vista como instrumento a serviço da democratização que começa na comunidade, pela discussão dos problemas da vida dos indivíduos e do grupo social, pela discussão da existência numa 'comunicação de consciências' que contribui para formar pessoas participantes num clima democrático-personalista e comunitário [...] (PAIVA, 1980, p. 97).

Paulo Freire concebe a educação como comunicação, diálogo: encontro de sujeitos que buscam a razão dos acontecimentos (FREIRE, 1996). Portanto, a educação é diálogo ou ela não é educação. Mas, Freire une o conceito de educação ao de cultura, vendo a cultura como o resultado da ação criadora do homem, da práxis humana (FREIRE, 1996). Para ele, a educação e a cultura devem andar juntas em uma relação dialética e prática. Assim, Paulo Freire vê o homem (livre) como criador de cultura quando constrói novos saberes pela práxis pedagógica fundada no diálogo. A única práxis pedagógica válida para ajudar os homens oprimidos a saírem da situação de opressão é a ação educacional fundada no diálogo. Nele, as figuras de professor e aluno são substituídas pela de educandos, pois ninguém educa ninguém, os homens se educam uns aos outros: "O educador não é mais aquele que somente ensina, mas aquele que, durante a ação educativa é também educado pelo diálogo com o educando" (FREIRE, 1996, p. 68).

Assim, a educação como instrumento de comunicação das consciências, propiciaria a formação de uma nova comunidade. Seria também um instrumento importante de combate à sociedade de massas dominada pela burguesia industrial urbana.

Da mesma forma, a comunicação é também uma categoria importante na obra de Mounier, como vimos nos capítulos anteriores do texto. De acordo com Moix (1968), para Mounier, a educação também está envolvida pelo diálogo enquanto "comunicação", que parte da realidade do povo, do oprimido:

[...] a educação deve elaborar uma formação do homem total; a cultura deve ser revivificada por novas elites de raízes populares; a vida pessoal, a vida privada, a vida pública, precisam ser transfiguradas. O personalismo deve dar linhas precisas de conduta que, por sua vez, devem ser sempre retomadas e adaptadas (MOIX, 1968, p.183).

A rigor, Mounier critica a natureza adaptativa presente nos seres humanos, como se tudo estivesse determinado. Da mesma forma, além da crítica ao Determinismo no conjunto de sua obra, Paulo Freire condena a adaptação, a acomodação e o ajustamento como fatores de massificação do homem. Para Mounier, o sistema capitalista faz com que o espírito de adaptação e o Determinismo que o sustenta estejam presentes na sociedade 
levando as pessoas a aceitarem sua condição de seres passivos. Mounier acredita que a adaptação demasiada é o mesmo que entregar-se aos acontecimentos. O homem que prefere o conforto à luta é um animal doméstico, ou melhor, domesticado, "reduzido à sua função produtora ou social" transformado em uma "peça numa engrenagem" (MOUNIER, 1970, p. 52). Mais adiante, o autor acrescenta que os homens em sua maioria preferem a segurança da escravidão ao risco da independência, "a vida material e vegetativa à aventura humana" (1970, p.107).

Nesse sentido, é importante transcrever uma passagem da obra de Freire, Educação como prática da liberdade (1979). Nela encontramos uma similaridade com o pensamento de Mounier, sobretudo quando Freire afirma que o homem é o ser da integração, ativo, transformador e não da acomodação, passivo, ajustado, acomodado. Afirma ele:

Portanto, enquanto o animal é essencialmente um ser da acomodação e do ajustamento, o homem é o da integração. A sua grande luta vem sendo, através dos tempos, a de superar os fatores que o fazem acomodado ou ajustado. É a luta por sua humanização, ameaçada constantemente pela opressão que o esmaga, quase sempre até sendo feita - e isso é o mais doloroso - em nome de sua própria libertação $(1979$, p. 43).

Ainda em Educação como prática da liberdade (1979), Freire faz mais considerações neste sentido:

[...] a acomodação exige uma dose mínima de criticidade. A integração, pelo contrário, exige um máximo de razão e consciência. É o comportamento característico dos regimes flexivelmente democráticos. O problema do ajustamento e da acomodação se vincula ao do mutismo a que já nos referimos, como uma das consequências imediatas de nossa inexperiência democrática. $\mathrm{Na}$ verdade no ajustamento o homem não dialoga. Não participa. Pelo contrário, se acomoda a determinações que se superpõem a ele $(1979$, p.74).

Dessa maneira, os trabalhos de Paulo Freire refletem a luta pela humanização do homem, seja ele oprimido ou opressor, pois para ele a libertação do oprimido é condição para a libertação do opressor. Da mesma forma, o pensamento de Paulo Freire, nas palavras de Gadotti (1996), é produto de sua trajetória existencial. Neste sentido, sua existência cristã engajada nos problemas sociais passa necessariamente pelo Personalismo de Mounier. Os momentos históricos em que viveu foram transbordados por este humanismo cristão.

Por mais que nas obras de Paulo Freire, analisadas aqui, não se encontrem referências diretas a Mounier, a não ser na nota de rodapé numero 54 da obra Educação como prática da liberdade, seu pensamento não foge das categorias epistemológicas desse autor. Isso pode ter acontecido, seja pela leitura direta dele, seja pela influência de Mounier no cenário intelectual nacional, assim como nos movimentos sociais católicos. Considerando esta afirmativa, mostramos que o Personalismo de Mounier está presente na sistematização do método de alfabetização Paulo Freire. Encontramos em Franco uma afirmação que corrobora essa afirmação: 
El influjo del personalismo es claro a través de Mounier. Pascal ya había dicho con clarividencia que "el hombre supera infinitamente al hombre"; y Paulo Freire asienta su método de alfabetización en el convencimiento pleno de que la persona es inobjetivable. El hombre es una realidad compleja y dinámica, y por eso mismo es el ser de la sorpresa en un doble sentido: es capaz de sorprenderse y admirarse ante cosas que ya han se desfilado otras muchas veces junto a él, y, sobre todo, tiene capacidad de reaccionar de forma imprevisible ante estímulos que le llegan "unívocamente" modelados; por eso, causa sorpresa en los demás cuando éstos están a la espera de un comportamiento uniforme y se encuentran con salidas no previstas (1973, p.22).

Por isso mesmo, a escolha da análise da obra Educação e atualidade Brasileira não se deu ao acaso. Ela foi selecionada para este texto, porque representa o período antes do exílio de Freire, período em que o seu pensamento era constituído por uma forte base epistemológica cristã. A partir da obra Pedagogia do oprimido publicada em 1968, Freire vê o binômio opressor-oprimido numa perspectiva mais crítica. Passa a utilizar categorias como a de luta de classes, assim como elementos originados do pensamento de Gramsci $^{3}$ no que se referia à participação dos intelectuais orgânicos no processo de libertação do oprimido. No entanto, a matriz teórica cristã não perde importância no ideário de Freire. Diríamos que ela perde um pouco sua visibilidade na medida em que Freire vai delimitando suas obras a partir de novos referenciais teóricos.

Franco (1973) procura clarificar essa questão dizendo que, a partir da Pedagogia do oprimido, o Personalismo continua presente nas ideias de Freire, sobretudo quando ele trata do diálogo. No entanto, para Franco, evidencia-se uma marca definitiva do Marxismo, em suas obras, que vai pouco a pouco se expandindo.

Neste sentido, Scocuglia, referindo-se à obra Pedagogia do Oprimido, afirma:

Enfatize-se, de passagem, que a aproximação marxiana-marxista é feita (não-dogmaticamente) através de parâmetros superestruturais relativos ao entendimento das conexões educação-consciência-ideologia-política. Coloque-se, ainda, que as correntes existencialistas/personalistas (definidoras do seu 'humanismo idealista' inicial) continuam presentes, agora misturadas com as incorporações do pensamento marxista. Na seqüência da sua obra (pós-Pedagogia do Oprimido), nos anos setenta, notaremos uma certa 'limpeza do terreno teórico' na tentativa de desfazer o 'amálgama' e encampar referências marxistas, a exemplo dos escritos de Antonio Gramsci (1999, p. 55).

Este texto, contudo, retrata o pensamento de Paulo Freire nas décadas de 1950 e 1960. Neste sentido, Heinz-Peter Gerhardt, no livro Paulo Freire uma biobibliografia, exemplifica bem as influências epistemológicas deste período de "emergência do povo" brasileiro na vida nacional.

A vida política brasileira, nos anos 50 e inicio da década de 60 , foi denominada a "emergência do povo" pelos defensores de um autêntico modelo de desenvolvimento para o país. Este grupo de intelectuais, dentre os quais se destacam Hélio Jaguaribe, Anísio Teixeira, Roland Corbisier e Álvaro Vieira Pinto, reunidos no Instituto Superior de Estudos Brasileiros (ISEB), no Rio de Janeiro, baseavam suas ideias em sociólogos e filósofos europeus como Karl Mannheim, Karl Jaspers, Gunnar Myrdal e Gabriel Marcel. Na 
universidade Freire tinha mais contacto com essa e outras tendências do pensamento brasileiro da época. Na sua participação no movimento católico leigo, ele também leu, cada vez mais, os autores da esquerda católica, como Jacques Maritain, Thomas Cardonnel, Emmanuel Mounier e seus radicais intérpretes brasileiros, Alceu Amoroso Lima, Henrique lima Vaz, Hebert José de Souza e outros (GERHARDT, In: GADOTTI, 1996, p. 153).

A seguir, esta investigação irá se deter na análise interpretativa da obra de Freire escrita antes do exílio. Procuraremos encontrar referências ou influências, diretas ou não, do Personalismo de Mounier e dos movimentos sociais católicos. Essa obra traz sua visão da história da educação no Brasil e da prática pedagógica dominante. Trata-se, portanto, de uma obra nitidamente teórica.

\section{A PRESENÇA DO PERSONALISMO NA OBRA EDUCAÇÃO E ATUALIDADE BRASILEIRA}

Em Educação e atualidade brasileira (2001), Paulo Freire, ao buscar referenciais dos integrantes do ISEB, apresenta de forma crítica a atualidade brasileira. Ele o faz a partir de uma antinomia principal, a qual é encontrada seguidamente ao longo do texto. A antinomia "inexperiência democrática e a emersão do povo na vida pública" subjaz a outros conceitos trabalhados pelo autor, como assistencialização, populismo, produção em série. Ou seja, tudo que leva à alienação, industrialização e massificação do homem, além de influenciar os níveis de consciência.

A inautenticidade e inorganicidade da educação são apresentadas por Freire no terceiro capítulo da obra. Para o autor, a educação tal como era desenvolvida não colaborava com o despertar da consciência transitiva crítica nos homens.

Romão (In: FREIRE, 2001), ao contextualizar a obra, afirma que Mounier não consta das referências bibliográficas de educação e atualidade brasileira. No entanto, por fazer parte do quadro ideológico do pós-guerra, o pensamento personalista está contido nas ideias de Freire e também na sistematização da apresentação da realidade brasileira no livro.

O depoimento de Paulo Rosas (In:FREIRE, 2001) é também de fundamental importância nesta edição de Educação e atualidade Brasileira. Rosas deixa clara a importância da presença da Igreja Católica e de seus movimentos sociais no Nordeste, principalmente, no tocante à participação dos jovens católicos. Estes questionam o conservadorismo da Igreja e engajam-se nas lutas sociais.

Entrando no texto propriamente dito, identificamos um ponto de influência do Personalismo, quando o autor faz a crítica à "assistencialização". Freire a conceitua como sendo:

[...] o máximo de passividade do homem diante dos acontecimentos que o envolvem. Opõe-se ao conceito nosso de 'dialogação', que coincide com o de 'parlamentarização' do professor Guerreiro Ramos. Enquanto na 'assistencialização' o homem queda mudo e quieto, na 'dialogação' ou na 'parlamentalização' o homem rejeita posições quietistas e se faz participante. Interferente. $\mathrm{O}$ assistencialismo é uma dimensão da assistencialização (FREIRE, 2001, p. 28) .

A "assistencialização" é retratada por Freire como estratégia antidemocrática da estrutura social, pois conservava o mutismo e o quietismo nos homens. Esta categoria foi igualmente criticada, na dimensão do assistencialismo, pelos católicos 
progressistas no Brasil. Beisiegel (1989) afirma que se tratava de uma temática "cara" aos círculos progressistas da Igreja.

A partir das análises feitas, confirmamos que os católicos, assim como Paulo Freire, viam igualmente essa questão sob a ótica personalista de Mounier. Para eles, "assistencialização" (Paulo Freire) e assistencialismo (católicos progressistas), impediriam o processo de tomada de consciência do homem, assim como aviltavam o poder de afrontamento deste.

Ao discutir as fases estruturais pelas quais passou o país, Freire apontava a necessidade do "diálogo". Este seria como "um instrumento de promoção da consciência perigosamente acrítica ou transitivo-ingênua, em que se encontra o homem brasileiro, nos centros urbanos, para a consciência transitivo-crítica, vital à democracia" (FREIRE, 2001, p. 31).

Para ele, o estudo da consciência, ou melhor, dos estágios de consciência do homem brasileiro se fazia necessário. Iria explicar a inexperiência democrática do povo e a importância de se planejar uma ação educativa que propiciasse uma emersão do povo brasileiro na vida política nacional.

Neste sentido, Freire tratou da consciência intransitiva presente nos homens que centralizavam seus interesses no que o autor chamou de formas vegetativas de vida. Segundo ele:

[...] suas preocupações se cingem mais ao que há nele de vital, biologicamente falando. Sua consciência é intransitiva nestas circunstâncias. É a consciência dos homens de zonas pouco ou nada desenvolvidas do país. Falta-lhe historicidade, ou, mais exatamente, teor de vida em plano mais histórico. São uns 'demitidos da vida' ou, talvez mais precisamente, uns inadmitidos à vida [...] (FREIRE, 2001, p. 32).

Esta posição é superada quando o homem vai além dos interesses vegetativos. Ao alargar seus horizontes, sua consciência torna-se transitiva. Caracteriza-se, segundo Freire, por "uma forte dose de espiritualidade, de historicidade, [...] corresponde às zonas de desenvolvimento econômico mais forte" (2001, p. 32).

Freire atribui relativa importância ao processo de industrialização nesse sentido, pois uma sociedade que se industrializa cresce economicamente. Por conseguinte, o estágio de consciência dos homens tende a evoluir do intransitivo ao transitivo, ainda que este seja um estágio ingênuo.

A consciência transitiva ingênua é marcada por uma "impermeabilidade à investigação", pela "fragilidade de argumentação", pela "tendência ao conformismo" (2001, p. 34). Portanto, deve a consciência transitiva ingênua avançar no sentido de tornarse transitividade crítica.

Freire explica que a transitividade crítica: 
[...] se caracteriza pela profundidade na interpretação dos problemas. Pela substituição de explicações mágicas por princípios causais. Por procurar testar os 'achados' e se dispor sempre a revisões. Por despir-se ao máximo de preconceitos na análise dos problemas. Na sua apreensão, esforçar-se por evitar deformações. Por negar a transferência da responsabilidade. Pela recusa de posições quietistas. Pela aceitação da massificação como um fato, esforçando-se, porém, pela humanização do homem. Por segurança na argumentação. Pelo gosto do debate. Por maior dose de racionalidade. Pela apreensão e receptividade a tudo que é novo. Por se inclinar sempre à arguições (2001, p. 34).

Quando Freire apresenta estas fases que permeiam a consciência do homem brasileiro, ele não escapa da ideia de tomada de consciência de Mounier. Para Mounier esta prise de conscience está ligada à restauração do sentido e da dignidade da pessoa. Esta dignidade foi corrompida pelo "individualismo pequeno burguês e pelas fraquezas do capitalismo", como denunciou Mounier (1970), (2003a), (2003b). Assim, a tomada de consciência tal como entendia Mounier era algo difícil, considerando-se a tendência do ser humano à acomodação e à estabilidade (RUEDELL, 1985, p.33).

Freire não deixa de denunciar as estruturas arcaicas do sistema econômico. De igual modo, denuncia uma educação atrelada à manutenção do status quo, da ordem social, uma educação que não desperta nos homens seu potencial de seres transitivos, ou de "afrontamento" como diria Mounier. Para Freire, a escola "superposta à nossa realidade acadêmica, propedêutica, e seletiva, por todas estas coisas antidemocráticas, vem constituindo um dos pontos mais fortes de sufocação do desenvolvimento econômico do país e da sua democratização" (FREIRE, 2001, p. 47).

Para Lacroix (1950), Mounier era um profeta da educação. Neste texto, sustentamos que tanto ele quanto Freire exerceram um verdadeiro profetismo. Isto, primeiro, no sentido de denunciar as estruturas sociais que desfavoreciam a libertação dos homens; segundo, por anunciar a possibilidade de transformá-las por meio de uma educação conscientizadora.

De acordo com Freire:

[...] uma educação que possibilite ao homem discussão corajosa de sua problemática. De sua inserção nesta problemática. Que o coloque em diálogo constante com o outro. Que o predisponha a constantes revisões. À análise crítica de seus "achados". A uma certa rebeldia no sentido mais humano da expressão. Que o identifique com métodos e processos científicos. Não há como concebermos uma educação, numa sociedade democratizando-se, que leve o homem a posições quietistas. Que não faça dele um ser cada vez mais consciente de sua transitividade, que deve ser usada tanto quanto possível criticamente ou com acerto cada vez maior de racionalidade (2001, p.38).

O diálogo é uma categoria presente no pensamento de Mounier e também no de Freire. Em Freire (EAB, 2001), o diálogo tem grande importância na superação da antinomia tratada no texto. Ele seria o ponto central do processo educativo libertador, e que compôs a base do seu método de alfabetização tempos depois.

É importante transcrever uma parte do parágrafo da obra de Freire, no qual ele explica a relação entre a dialogação e a transitividade, argumentando que, para haver diálogo, o homem precisa ter superado sua intransitividade. 
Para ele,

[...] esta transitividade da consciência permeabiliza o homem. Faz dele um ser mais vibrátil. Leva-o a vencer o seu quase que incompromisso com a existência, característico da consciência intransitiva, e o compromete quase totalmente. Por isso mesmo que existir é um conceito dinâmico. Implica uma dialogação eterna do homem com o homem, do homem com a circunstância. Do homem com seu Criador. Não há como se admitir o homem fora do diálogo. E não há diálogo autêntico sem um mínimo de consciência transitiva. É essa dialogação do homem em torno das sugestões e até com as sugestões que o faz histórico. Por isso nos referimos ao quase incompromisso do homem intransitivamente consciente com a sua existência. $\mathrm{E}$ ao plano de vida mais vegetativo que histórico, característico da intransitividade (FREIRE, 2001, p. 35).

Em Mounier, estas ideias se complementam quando ele fala da "afirmação de si”, dada naturalmente por meio da comunicação. Para ele, a comunicação (diálogo) seria o meio possível para ajudar o homem a emergir de sua consciência intransitiva. Neste sentido, o homem seria capaz de reagir aos "événéments", aos acontecimentos de sua existência, tomar de-cisões, posicionar-se, afrontar.

Neste sentido, é preciso despertar nos homens esta capacidade de afrontar. Para isso, porém, é preciso libertar-se das seduções do mundo material. Explica-se, pois "a revolta em tempo de domesticação, a resistência à opressão, a recusa face ao aviltamento são privilégios inalienáveis da pessoa, seu último recurso quando o mundo se levanta contra seu reino" (MOUNIER, 1970, p.107).

A capacidade de afrontar presente no ser humano seria o que Paulo Freire chamou de criticidade. Esta, por sua vez, só seria despertada por meio de uma educação pelo diálogo, pela participação e não mais pela assistencialização e pelo quietismo enraizados em "nossa inexperiência democrática" (FREIRE, 2001).

$\mathrm{Na}$ terceira parte da obra, Freire faz novamente uma crítica às condições limitadoras da antinomia. Era a "inexperiência democrática/ emersão do povo brasileiro na vida política nacional" em uma sociedade que se fazia industrializando-se e que se queria democrática. Sobretudo concentra sua crítica ao sistema educacional contemporâneo, no que tange à sua inorganicidade. Em contraponto, propõe uma educação democratizadora.

Freire aposta em uma educação mais comunitária, regional e que parta das diversidades culturais de cada região. Ela deve identificar o educando com seu tempo e seu espaço e denunciar o abuso de uma educação "vinda de cima", centralizada e centralizadora. Seria uma educação "solidária", baseada mais na obra de Fernando Bastos de Ávila (Solidarismo e neocapitalismo), do que em Tristão de Athayde, como esclareceu Saviani (2008).

Afirma Freire: 


\begin{abstract}
Desta forma encaminhemos o nosso agir educativo no sentido da consciência do grupo, e não no da ênfase exclusiva do indivíduo. Sentimento grupal que nos é lamentavelmente ausente. As condições histórico-culturais em que nos formamos e que analisamos no capitulo anterior nos levaram a esta posição individualista. Impossibilitaram a criação do homem 'solidarista', só recentemente emergindo das novas condições culturais que vivemos, mas indeciso nessa solidariedade e necessitando, por isso mesmo, de educação fortemente endereçada neste sentido. De educação que deve desvestir-se de todo ranço, de todo estímulo a esta culturológica marca individualista. Que dinamize, ao contrário, o espírito comunitário (FREIRE, 2001, p. 85).
\end{abstract}

Vemos que Freire se preocupou em instaurar, assim como Mounier, uma comunidade de pessoas. Para isso, utilizou-se da educação. De uma educação que deveria estar a serviço da desmassificação do homem, da libertação da cultura individualista pequeno-burguesa e que o inserisse em sua historicidade, e que também o fizesse reagir aos acontecimentos. Dessa forma, ele iria ser valorizado como fazedor de cultura.

Esta seria uma educação de inspiração personalista, aquela que "não consiste na aquisição de um volume de informações e de habilidades, nem na preparação profissional ou no desempenho de uma função social, e sim no 'despertar da pessoa"" (LORENZON, 1996, p. 67). Esse despertar torna o homem um ser conscientizado de seu lugar e de seu agir no processo histórico e na vida política nacional, como disse Freire (2001).

Para Freire, as escolas devem ser verdadeiros centros comunitários, que eduquem alunos e familiares "no sentido da responsabilidade social e política". Deve também estimular a comunidade escolar "na análise crítica da problemática local, regional e nacional" (FREIRE, 2001, p. 96).

A importância das escolas inseridas no contexto da comunidade se dá também no sentido de se fazerem independentes no que se refere à sua organização e currículo. Isto não quer dizer, segundo Freire, que aspectos da vida nacional não devam ser trabalhados igualmente em todas as escolas. Deve-se, porém, evitar uma totalitarização do processo educativo. Esse processo, segundo Mounier, leva à neutralidade da educação. Por isso, para Mounier somente uma escola pluralista seria capaz de combater os perigos de uma educação neutra e totalitária.

Enfim, em Educação e Atualidade Brasileira (2001), Paulo Freire se preocupou em fazer uma análise da situação política e social do país por meio de uma retomada histórica. Denunciou também a inorganicidade da educação no processo de desenvolvimento democrático da nação. Nesse período, Freire apresentou a necessidade de uma mudança na forma como a educação era compreendida, a fim de contribuir para a mudança da sociedade em transição. Da mesma forma, Mounier denunciou essa mesma deficiência na educação, quando se preocupou com a formação utilitarista que se dava às crianças nas escolas em sua época.

\title{
CONSIDERAÇÕES FINAIS
}

Levando em consideração as reflexões feitas neste artigo, é importante salientar que as ideias pedagógicas de Paulo Freire, bem como a elaboração de seu método são produtos de sua trajetória existencial. Produtos de sua vivência cristã engajada em favor da mudança social. A vivência das fases pelas quais passou a nação (estudadas por Freire) fez com que ele entrasse em contato com o Personalismo de Mounier. Desta forma, Freire se 
familiarizou bastante com os chamados católicos radicais, sobretudo na década de 1950 . Além disto, foi igualmente influenciado pelos intelectuais do ISEB na análise da realidade brasileira, e alguns destes, por sua vez, receberam influência do Personalismo.

Não é por acaso que as categorias do pensamento de Mounier estão presentes na obra de Paulo Freire do período de 1950 e 1960, neste caso, em Educação e Atualidade Brasileira (2001). Sua existência engajada, inspirada no Personalismo, entre outras correntes filosóficas, fez com que ele desenvolvesse seu método de alfabetização conscientizador. É um método que refletia algumas das categorias do pensamento de Mounier, como, por exemplo, a "tomada de consciência revolucionária". Ou seja, a ideia de que a conscientização despertaria o educando para a ação transformadora no mundo, uma ação cultural para a liberdade.

Sua parceria com os jovens católicos se deu no combate à massificação, segundo Paiva (1980). Os jovens viam no método de alfabetização de Paulo Freire um mecanismo capaz de ajudá-los a lutar contra a massificação. Este seria um dos motivos da utilização de seu método na ação do MEB, por exemplo.

No que diz respeito às analises das obras Educação e atualidade brasileira (2001), puderam ser percebidas, mescladas aos escritos de Freire, muitas ideias que remetem às categorias do Personalismo, analisadas no corpo do texto. Entre elas se encontram a crítica ao determinismo, à assistencialização, ao modelo educacional, à importância dada ao diálogo e à comunicação. Esses são apenas alguns dos indícios da presença das ideias de Mounier no pensamento pedagógico de Paulo Freire.

Contudo, o profetismo presente no pensamento e na obra desses dois autores, talvez seja um dos pontos mais expressivos da influência de Mounier sobre as ideias de Paulo Freire. A denúncia e o anúncio, características da função profética foi algo presente no conjunto da obra de Freire. Do mesmo, aconteceu na de Mounier. Ambas denunciavam as estruturas dominadoras e escravizantes da sociedade e anunciavam a possibilidade de mudanças "inédito viável", tendo a educação como parte integrante do anúncio e da compreensão da denúncia.

Ao aproximarmos as ideias de Paulo Freire às de Mounier, quisemos evidenciar, sobretudo, que seu pensamento pedagógico partiu da análise da realidade brasileira, sob a ótica personalista, e da vivência do próprio Freire junto aos movimentos sociais católicos. Esse processo permitiu que Freire desenvolvesse com os jovens católicos uma ação transformadora por meio de um instrumento conscientizador, que foi seu método de alfabetização. Dessa maneira, ao procurarmos verificar a influência do Personalismo de Emmanuel Mounier em Paulo Freire, concluímos que não somente houve uma articulação entre as ideias dos dois, mas, que houve, ainda, uma influência de Mounier sobre Freire.

\section{REFERÊNCIAS}

BEISIEGEL,Celso de Rui. Política e educação popular. São Paulo: Ática, 1989.

FRANCO, Fausto. El hombre: construcción progresiva. La tarea educativa de Paulo Freire. Madrid: Marsiega, 1973.

FREIRE, Paulo. Educação como pratica da liberdade. 9 ed. Rio de Janeiro: Paz e Terra, 1979.

Educação e atualidade brasileira. São Paulo: Cortez, 2001.

Pedagogia do Oprimido. Rio de Janeiro: Paz e Terra. 1996.

GADOTTI, Moacir. Paulo Freire: uma biobibliografia. São Paulo: Cortez, 1996.

GERHARDT, Heinz-Peter. Uma voz européia: Arqueologia de um pensamento. In: GADOTTI, Moacir. Paulo Freire: uma biobibliografia. São Paulo: Cortez, 1996. 
GRAMSCI, Antônio. Cadernos do cárcere. Rio de Janeiro: Civilização Brasileira, 20002001.

Brasileira, 1978.

Os intelectuais e a organização da cultura. 2 ed. Rio de Janeiro: Civilização LACROIX, Jean. Mounier Educateur. Esprit, n. 12, 1950.

LORENZON, Alino. Atualidade do pensamento de Emmanuel Mounier. Ijuí: Universidade Regional do Noroeste do Estado do Rio Grande do Sul, 1996.

MOIX, Candide. O pensamento de Emmanuel Mounier. Rio de Janeiro: Paz e Terra, 1968.

MOUNIER, Emmanuel. O Personalismo. Lisboa: Moraes, 1970.

Manifeste au service du personnalisme. Paris : Du Seuil, 1961 et février 2003b. (version numérique)

Révolution personnaliste et communautaire. Paris : Du Seuil, 1961 et février 2003a. (version numérique)

PAIVA, Vanilda Pereira. Paulo Freire e o nacionalismo-desenvolvimentista. Rio de Janeiro: Civilização Brasileira, 1980.

ROMÃO, José Eustáquio. Contextualiação: Paulo Freire e o Pacto Populista. In: FREIRE, Paulo. Educação e atualidade brasileira. São Paulo: Cortez, 2001.

ROSAS, Paulo. Depoimento I Recife - Cultura e Participação (1950-1964). In: FREIRE, Paulo. Educação e atualidade brasileira. São Paulo: Cortez, 2001.

RUEDELL, Aloisio. Lições políticas para a América Latina. Canoas, RS: La Salle, 1985.

SAVIANI, Dermeval. História das idéias pedagógicas no Brasil. Campinas, SP: Autores Associados. 2008.

SCOCUGliA, Afonso Celso. A História das idéias de Paulo Freire e a atual crise de paradigmas. João Pessoa: Ed. Universitária / UFPB, 1999.

WANDERLEY, Luiz Eduardo W. Educar para transformar: educação popular, Igreja Católica e política no movimento de educação de base. Petrópolis, RJ: Vozes, 1984.

\footnotetext{
${ }^{1}$ Possui graduação em Pedagogia pela Pontifícia Universidade Catolica do Paraná (2009) com estágio em Mobilité à l'université de Fribourg - Université de Fribourg - Suisse (2008), Mestrado em Educação pela Pontifícia Universidade Catolica do Paraná (2012) e Doutorado em Educação, em andamento, pela mesma instituição. Atualmente é professor de Fundamentos da Educação - Unespar - Campus FAFIPAR. Tem experiência na área de Educação, com ênfase em Fundamentos da Educação, atuando principalmente nos seguintes temas: educação, instrução pública, organização da escola e educação; política educacional; intelectuais católicos; história e filosofia da Educação

${ }^{2}$ Cf. capitulo 4 do Livro Paulo Freire uma Biobibliografia organizado por Moacir Gadotti, (1996).

${ }^{3}$ Cf. GRAMSCI, Antônio. Cadernos do cárcere. Rio de Janeiro: Civilização Brasileira, 2000-2001.

Cf. GRAMSCI, Antônio. Os intelectuais e a organização da cultura. Rio de Janeiro: Civilização Brasileira, 1978.

${ }^{4}$ Cf. nota 9 in: EAB.

${ }^{5}$ Conceito de Álvaro Vieira Pinto, aqui apresentado sob a visão de Paulo Freire.
} 